\title{
Using Illness Rating Systems to Predict Discharge Location Following Total Knee Arthroplasty
}

\author{
Sarah Rudasill, BA ${ }^{1}$, Jonathan R. Dattilo, $\mathrm{MD}^{2}$, Jiabin Liu, $\mathrm{MD}^{3}$, Ari Clements ${ }^{4}$, Charles L. Nelson, $\mathrm{MD}^{2}$, \\ and Atul F. Kamath, $\mathrm{MD}^{2}$ \\ ${ }^{1}$ David Geffen School of Medicine, Los Angeles, CA; ${ }^{2}$ Department of Orthopaedic Surgery, University of Pennsylvania, Philadelphia, PA; ${ }^{3}$ Department of Anesthesiology, \\ University of Pennsylvania, Philadelphia, PA; ${ }^{4}$ University of Pennsylvania, Philadelphia, PA, USA
}

\begin{abstract}
Purpose: Total knee arthroplasty (TKA) is increasing in frequency and cost. Optimization of discharge location may reduce total expenditure while maximizing patient outcomes. Although preoperative illness rating systems-including the American Society for Anesthesiologists Physical Classification System (ASA), severity of illness scoring system (SOI), and Mallampati rating scale (MP)—are associated with patient morbidity and mortality, their predictive value for discharge location, length of stay (LOS), and total costs remains unclear.

Materials and Methods: We conducted a retrospective analysis of 677 TKA patients (550 primary and 127 revision) treated at a single institution. The influence of ASA, SOI, and MP scores on discharge locations, LOS, and total costs was assessed using multivariable regression analyses.

Results: None of the systems were significant predictors of discharge location following TKA. SOI scores of major or higher $(\beta=2.08$ days, $\mathrm{p}<0.001)$ and minor $(\beta=-0.25$ days, $p=0.009)$ significantly predicted LOS relative to moderate scores. Total costs were also significantly predicted by SOI scores of major or higher $(\beta=\$ 6,155, \mathrm{p}=0.022)$ and $\operatorname{minor}(\beta=-\$ 1,163, \mathrm{p}=0.007)$.

Conclusions: SOI scores may be harnessed as a predictive tool for LOS and total costs following TKA, but other mechanisms are necessary to predict discharge location.
\end{abstract}

Keywords: Knee, Osteoarthritis, Arthroplasty

\section{Introduction}

Total knee arthroplasty (TKA) is the standard of surgical care for patients with debilitating knee osteoarthritis ${ }^{1)}$. The demand for primary and revision TKAs is expected to rise by $637 \%$ to almost 3.5 million annual procedures by $2030^{2}$. While bundled care initiatives have emerged to control rising costs, post-discharge expenditures comprise as much as $55 \%$ of the total payment for an episode ${ }^{3-5)}$. Discharge to extended care facilities (ECF),

Received October 16, 2017; Revised (1st) December 3, 2017;

(2nd) December 15, 2017; Accepted January 5, 2018

Correspondence to: Sarah Rudasill, BA

David Geffen School of Medicine, 925 Weyburn Place, Apt. 429, Los

Angeles, CA 90024, USA

Tel: +1-717-479-0589

E-mail: srudasill@ucla.edu

This is an Open Access article distributed under the terms of the Creative Commons Attribution Non-Commercial License (http://creativecommons.org/licenses/by-nc/4.0/) which permits unrestricted non-commercial use, distribution, and reproduction in any medium, provided the original work is properly cited. which include both skilled nursing facilities (SNFs) and acute rehabilitation facilities, accounts for up to $70 \%$ of these postdischarge payments ${ }^{5}$.

Preoperative illness rating systems have been leveraged to predict outcomes following joint arthroplasty. The American Society of Anesthesiologists physical status classification system (ASA) is a common preoperative assessment that classifies patients into one of six categories indicating disease progression ${ }^{6)}$. In total hip and knee arthroplasty patients, ASA scores $\geq 3$ have been associated with increased morbidity and mortality, as well as increased hospital readmissions (odds ratio [OR], 2.9) ${ }^{6,7)}$. While there is some evidence to suggest that ASA scores are correlated with total costs, their predictive value for discharge following TKA is unclear $^{8)}$.

Other illness rating systems may also predict discharge location and outcomes. The severity of illness scoring system (SOI) score estimates a patient's disease progression with four stages, encompassing minor, moderate, major, and extreme disease ${ }^{9)}$. Higher SOI scores are associated with an average increase in mean to- 
tal costs of $23 \%-29 \%$ and increased resource utilization in the operating room for joint arthroplasty ${ }^{10-12)}$. There may also be a relationship between SOI scores and postoperative functional outcomes and lengths of stay (LOS), but the ability of SOI scores to predict discharge following TKA is unexplored ${ }^{12)}$. In addition, Mallampati rating scale (MP) scores are a preoperative rating system that has been largely unexamined for predictive value. Scaled from a low risk (1) to a high risk (4), MP scores reflect the estimated difficulty of patient intubation.

The widespread adoption and utilization of preoperative illness rating systems could make them valuable predictive tools. The purpose of this study was to examine the predictive value of ASA, SOI, and MP scores in predicting discharge location, LOS, and total costs for TKA patients. The present study hypothesized that one or more of these preoperative illness rating systems could significantly predict patient discharge location to optimize LOS and total costs.

\section{Materials and Methods}

We retrospectively analyzed patients at a single institution undergoing TKA from May 2011 to April 2012. The Institutional Review Board (IRB) approved this study under the IRB protocol number 814466. Patients were identified using Current Procedural Terminology (CPT) codes for primary TKA $(27445,27446$, and 27447) and revision TKA (27486 and 27487), resulting in 736 unique patient records. Patients were excluded for missing ASA scores (5), MP scores (11), body mass index (BMI) (8), and anesthesia type (25). Additionally, 4 non-elective procedures were excluded, as were 5 hospital transfers and 1 early death. As shown in Fig. 1, this resulted in 677 records remaining for analysis.

Three discharge classes were created based on discharge to home, skilled nursing facility, or rehabilitation facility. All commercial and private insurers-including point-of-service plans, preferred provider organizations, health maintenance organizations, traditional plans, and university plans-were grouped into private insurance. Medicaid and Medicaid traditional/indemnity were grouped together as Medicaid. The few patients covered by military tri-care (13), worker's compensation (6), and auto insurance traditional/indemnity (2) were grouped into a category for other insurance.

Multivariable regressions evaluated the impact of demographic factors and illness rating systems on discharge location, LOS, and total costs for an episode. These factors included age, race, sex, BMI, type of anesthesia, revision status, and insurance coverage. Patients were stratified into two groups by ASA scores: ASA $\leq 2$ or

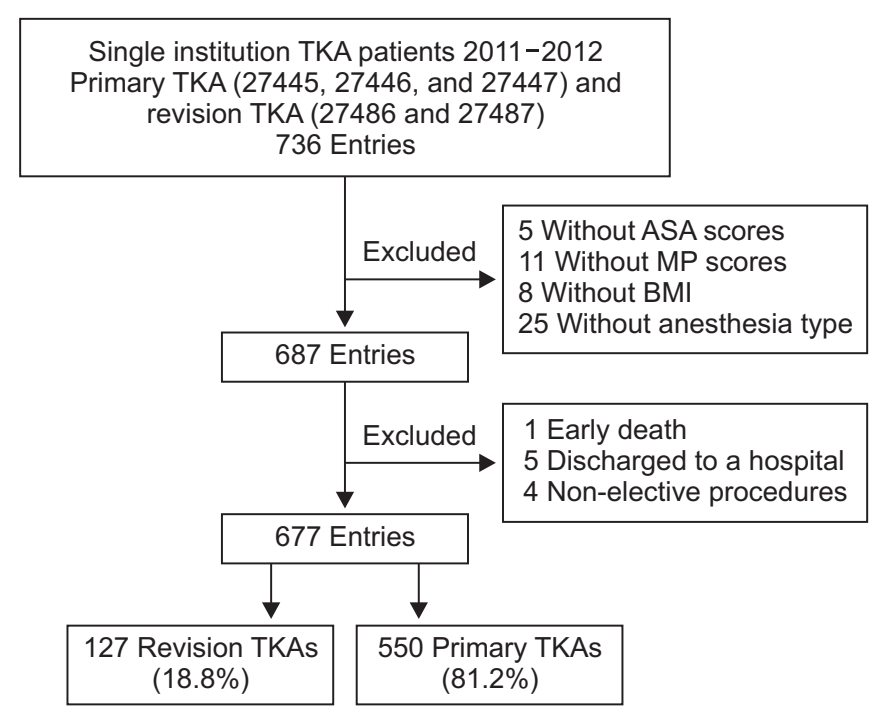

Fig. 1. Sample selection and exclusion criteria. The process for selecting patients for analysis is outlined, with reasons for exclusions and the number excluded noted. TKA: total knee arthroplasty, ASA: American Society for Anesthesiologists physical classification system, MP: Mallampati rating scale, BMI: body mass index.

$\mathrm{ASA} \geq 3$. For SOI scores, major and extreme ratings were grouped together into major+ given the small number (2) of extreme ratings. For MP scores, ratings of 3 and 4 were grouped into MP scores $3+$ because of the small percentage $(1.8 \%)$ at the highest score.

Discharge to SNFs, rehabilitation facilities, and home were analyzed using logistic regressions and tested via the link test to ensure choice of meaningful predictors while avoiding specification error. LOS and total costs were analyzed with ordinary least squares robust regression to account for failures in normality, heteroskedasticity, and large residuals. Significance was analyzed at a 0.05 level. Analyses were performed using STATA ver. 12.1 (StataCorp LP, College Station, TX, USA).

\section{Results}

Patient demographics are shown in Table 1. The 677 patients were predominantly African-American (49.9\%) and Caucasian (43.1\%). Most patients were discharged to SNFs (62.3\%), and revisions constituted $18.8 \%$ of procedures. The majority of patients were assigned moderate preoperative scores, with $96.7 \%$ of the cohort scoring at ASA 2 or 3, 95.6\% scoring at SOI of moderate or minor, and $76.4 \%$ scoring at MP 1 or 2 .

None of the preoperative illness rating systems was a significant predictor of discharge to SNFs, home, or rehabilitation centers, as shown in Table 2. Discharge to SNF was not significantly predict- 
52 Rudasill et al. Predictors of Discharge Location in Total Knee Arthroplasty

Table 1. Demographic Distribution of Total Knee Arthroplasty Patients

\begin{tabular}{|c|c|c|c|c|}
\hline Factor & Caucasian $(\mathrm{n}=292)$ & African-American $(\mathrm{n}=338)$ & Other $(n=47)$ & Total $(n=677)$ \\
\hline \multicolumn{5}{|l|}{ ASA score } \\
\hline 1 & 3.4 & 1.5 & 4.3 & 2.5 \\
\hline 2 & 46.9 & 47.6 & 76.6 & 49.3 \\
\hline$\leq 2$ & 50.3 & 49.1 & 80.9 & 51.8 \\
\hline 3 & 48.3 & 50.6 & 19.1 & 47.4 \\
\hline 4 & 1.4 & 0.3 & 0.0 & 0.7 \\
\hline$\geq 3$ & 49.7 & 50.9 & 19.1 & 48.2 \\
\hline \multicolumn{5}{|l|}{ SOI score } \\
\hline Major+ & 6.2 & 3.6 & 0.0 & 4.4 \\
\hline Moderate & 43.2 & 44.1 & 25.5 & 42.4 \\
\hline Minor & 50.7 & 52.4 & 74.5 & 53.2 \\
\hline \multicolumn{5}{|l|}{ MP score } \\
\hline 1 & 27.4 & 28.4 & 29.8 & 28.1 \\
\hline 2 & 49.0 & 48.5 & 48.9 & 48.7 \\
\hline 3 & 21.6 & 21.6 & 19.1 & 21.4 \\
\hline 4 & 2.1 & 1.5 & 2.1 & 1.8 \\
\hline \multicolumn{5}{|l|}{ Discharge location } \\
\hline SNF & 54.5 & 68.6 & 66.0 & 62.3 \\
\hline Rehabilitation facility & 16.8 & 13.9 & 14.9 & 15.2 \\
\hline Home & 28.8 & 17.5 & 19.1 & 22.5 \\
\hline \multicolumn{5}{|l|}{ Insurance status } \\
\hline Medicaid & 13.4 & 30.2 & 44.7 & 23.9 \\
\hline Medicare & 40.4 & 46.7 & 36.2 & 43.3 \\
\hline Private insurance & 42.5 & 20.4 & 17.0 & 29.7 \\
\hline Other insurance & 3.8 & 2.7 & 2.1 & 3.1 \\
\hline \multicolumn{5}{|l|}{ Sex } \\
\hline Male & 43.8 & 28.7 & 34.0 & 35.6 \\
\hline Female & 56.2 & 71.3 & 66.0 & 64.4 \\
\hline \multicolumn{5}{|l|}{ Anesthesia } \\
\hline General & 21.6 & 22.5 & 23.4 & 22.2 \\
\hline General+regional block & 69.9 & 71.3 & 72.3 & 70.8 \\
\hline Spinal & 8.6 & 6.2 & 4.3 & 7.1 \\
\hline \multicolumn{5}{|l|}{ Metric } \\
\hline Revision & 24.0 & 15.4 & 10.6 & 18.8 \\
\hline Complications & 0.7 & 0.6 & 0.0 & 0.6 \\
\hline Average age (yr) & $37.2 \pm 11.6$ & $36.7 \pm 10.8$ & $39.1 \pm 12.2$ & $37.1 \pm 11.2$ \\
\hline Average BMI $\left(\mathrm{kg} / \mathrm{m}^{2}\right)$ & $33.4 \pm 7.6$ & $34.2 \pm 7.6$ & $30.5 \pm 5.9$ & $33.6 \pm 7.6$ \\
\hline \multicolumn{5}{|l|}{ Outcomes } \\
\hline Average LOS (day) & $3.6 \pm 2.0$ & $3.4 \pm 1.2$ & $3.2 \pm 0.8$ & $3.5 \pm 1.6$ \\
\hline Average total cost (\$) & $14,975 \pm 7,830$ & $13,444 \pm 4,659$ & $13,021 \pm 4,550$ & $14,075 \pm 6,265$ \\
\hline
\end{tabular}

Values are presented as mean \pm standard deviation or percentage.

ASA: American Society for Anesthesiologists physical classification system, SOI: severity of illness scoring system, MP: Mallampati rating scale, SNF: skilled nursing facility, BMI: body mass index, LOS: length of stay. 
Table 2. A p-value Matrix of Rating Systems on Discharge Location, Length of Stay (LOS), and Total Cost

\begin{tabular}{lccccc}
\hline \multicolumn{1}{c}{ Rating } & SNF & $\begin{array}{c}\text { Rehabilitation } \\
\text { facility }\end{array}$ & Home & LOS & Total cost \\
\hline ASA $\geq 3$ & 0.751 & 0.708 & 0.869 & 0.099 & 0.152 \\
SOI major+ & 0.296 & 0.657 & 0.162 & $<0.001$ & 0.022 \\
SOI minor & 0.842 & 0.098 & 0.112 & 0.009 & 0.007 \\
MP score 2 & 0.746 & 0.768 & 0.370 & 0.930 & 0.786 \\
MP score 3+ & 0.424 & 0.917 & 0.179 & 0.746 & 0.953 \\
\hline
\end{tabular}

SNF: skilled nursing facility, ASA: American Society for Anesthesiologists physical classification system, SOI: severity of illness scoring system, MP: Mallampati rating scale.

ed by ASA scores $\geq 3$ ( $p=0.751)$, SOI scores of major $+(p=0.296)$ or minor $(p=0.842)$, or MP scores of $2(p=0.746)$ or $3+(p=0.424)$. Furthermore, none of the rating systems emerged as significant predictors even when rehabilitation and SNFs were combined into discharge to any extended care facility.

Table 3 shows the variables that predict discharge to an ECF. African-American patients were $71 \%$ more likely to be discharged to an ECF than Caucasian patients (OR, 1.71; p=0.016; 95\% confidence interval [CI], 1.10 to 2.64). Every one-year increase in age $(\mathrm{OR}, 1.08 ; \mathrm{p}<0.001 ; 95 \% \mathrm{CI}, 1.05$ to 1.10$)$ and $\mathrm{BMI}(\mathrm{OR}$, 1.07; $\mathrm{p}<0.001 ; 95 \% \mathrm{CI}, 1.03$ to 1.10$)$ increased the risk of ECF discharge. Although Medicaid was not a statistically significant predictor, it increased ECF discharge relative to private insurance. Revision procedures were the only variable associated with a significant decrease in the likelihood of ECF discharge relative to primary procedures (OR, $0.41 ; \mathrm{p}=0.001 ; 95 \% \mathrm{CI}, 0.25$ to 0.68 ). Table 4 displays the significant predictors of LOS. SOI scores were the only preoperative illness rating system that significantly predicted LOS. SOI scores of major $+(\beta=2.08$ days; $\mathrm{p}<0.001 ; 95 \%$ CI, 1.03 to 3.13 ) and minor ( $\beta=-0.25$ days; $p=0.009 ; 95 \% \mathrm{CI}$, -0.43 to -0.06 ) were significant predictors of patient LOS relative to patients with moderate SOI scores. Age $(\beta=0.02 ; \mathrm{p}=0.003 ; 95 \%$ CI, 0.01 to 0.03 ) and $\mathrm{BMI}(\beta=0.03 ; \mathrm{p}=0.002 ; 95 \% \mathrm{CI}, 0.01$ to 0.06$)$ were the only other positive predictors of increased LOS. Race, sex, insurance coverage, and procedure type were not significant predictors.

Of all preoperative illness rating systems, SOI scores were also the only significant predictors of total costs. SOI scores of major+ $(\beta=\$ 6,155 ; p=0.022 ; 95 \% \mathrm{CI}, \$ 877$ to $\$ 11,434)$ and minor $(\beta=-\$ 1,163 ; p=0.007 ; 95 \% C I,-\$ 2,209$ to $-\$ 317)$ were significant predictors of total costs relative to patients with moderate SOI scores. Other significant positive predictive factors for total costs included revision procedures $(\beta=\$ 6,321 ; \mathrm{p}<0.001 ; 95 \% \mathrm{CI}, \$ 4,590$
Table 3. Odds Ratios (ORs) for Independent Rating Systems and the Significant Predictive Factors of Discharge to Extended Care Facilities

\begin{tabular}{|c|c|c|c|c|}
\hline \multirow[b]{2}{*}{ Predictive factor } & \multicolumn{4}{|c|}{ Any post-discharge acute care } \\
\hline & $\begin{array}{l}\text { Unadjusted } \\
\text { OR }\end{array}$ & $\begin{array}{c}\text { Adjusted } \\
\text { OR }\end{array}$ & $\mathrm{p}$-value & $\begin{array}{c}95 \% \\
\mathrm{CI}\end{array}$ \\
\hline $\mathrm{ASA} \geq 3$ & 1.47 & 0.96 & 0.869 & $0.62-1.50$ \\
\hline $\begin{array}{l}\text { SOI major+ } \\
\text { vs. SOI moderate }\end{array}$ & 1.47 & 2.23 & 0.162 & $0.73-6.88$ \\
\hline $\begin{array}{l}\text { SOI minor } \\
\text { vs. SOI moderate }\end{array}$ & 0.66 & 0.69 & 0.112 & $0.44-1.09$ \\
\hline $\begin{array}{l}\text { MP score } 2 \\
\text { vs. MP score } 1\end{array}$ & 0.97 & 0.80 & 0.370 & $0.49-1.31$ \\
\hline $\begin{array}{l}\text { MP score 3+ } \\
\text { vs. MP score } 1\end{array}$ & 0.97 & 0.67 & 0.179 & $0.38-1.20$ \\
\hline \multicolumn{5}{|l|}{ Caucasian (ref) } \\
\hline African-American & 1.79 & 1.71 & 0.016 & $1.10-2.64$ \\
\hline Other race & 1.24 & 1.57 & 0.334 & $0.63-3.93$ \\
\hline \multicolumn{5}{|l|}{$\begin{array}{l}\text { General+regional } \\
\text { block (ref) }\end{array}$} \\
\hline Spinal & 1.28 & 1.21 & 0.656 & $0.53-2.78$ \\
\hline General & 0.68 & 0.71 & 0.152 & $0.44-1.13$ \\
\hline \multicolumn{5}{|l|}{ Private insurance (ref) } \\
\hline Medicaid & 0.93 & 1.69 & 0.064 & $0.97-2.95$ \\
\hline Medicare & 2.21 & 1.51 & 0.153 & $0.86-2.65$ \\
\hline Other insurance & 0.37 & 0.68 & 0.458 & $0.24-1.89$ \\
\hline Revision & 0.46 & 0.41 & 0.001 & $0.25-0.68$ \\
\hline Age (yr) & 1.07 & 1.08 & $<0.001$ & $1.05-1.10$ \\
\hline Body mass index $\left(\mathrm{kg} / \mathrm{m}^{2}\right)$ & 1.05 & 1.07 & $<0.001$ & $1.03-1.10$ \\
\hline Female & 1.83 & 1.34 & 0.165 & $0.89-2.02$ \\
\hline
\end{tabular}

CI: confidence interval, ASA: American Society for Anesthesiologists physical classification system, SOI: severity of illness scoring system, MP: Mallampati rating scale, ref: reference.

to $\$ 8,052)$ and patients covered by Medicare $(\beta=\$ 1,056 ; \mathrm{p}=0.030$; $95 \% \mathrm{CI}, \$ 100$ to $\$ 2,012)$ relative to those with private insurance. Female sex $(\beta=-\$ 909 ; p=0.030 ; 95 \% \mathrm{CI},-\$ 1,729$ to $-\$ 89)$ was the only independent predictor of reduced expenditure.

\section{Discussion}

As primary and revision TKAs increase in frequency, many institutions now subject the procedures to bundled payment initiatives to control rising costs ${ }^{2,4)}$. Since discharge location can account for a majority of the total cost for an episode, preoperative optimization of discharge location may permit a reduction in total expenditures ${ }^{3,5)}$. Existing illness rating scales like ASA physi- 
54 Rudasill et al. Predictors of Discharge Location in Total Knee Arthroplasty

Table 4. Effect Sizes for Significant Risk Factors in Severity of Illness Scoring System (SOI) Analysis

\begin{tabular}{|c|c|c|c|c|c|c|}
\hline \multirow{2}{*}{ Factor } & \multicolumn{3}{|c|}{ Length of stay (day) } & \multicolumn{3}{|c|}{ Cost $(\$)$} \\
\hline & $\beta$ & p-value & $95 \% \mathrm{CI}$ & $\beta$ & $\mathrm{p}$-value & $95 \% \mathrm{CI}$ \\
\hline \multicolumn{7}{|l|}{ SOI moderate (ref) } \\
\hline Major+ & 2.08 & $<0.001$ & 1.03 to 3.13 & $\$ 6,155$ & 0.022 & 877 to 11,434 \\
\hline Minor & -0.25 & 0.009 & -0.43 to -0.06 & $-\$ 1,163$ & 0.007 & $-2,209$ to -317 \\
\hline \multicolumn{7}{|l|}{ Caucasian (ref) } \\
\hline African-American & -0.21 & 0.109 & -0.47 to 0.05 & $-\$ 835$ & 0.056 & $-1,690$ to 20 \\
\hline Other & -0.17 & 0.293 & -0.48 to 0.14 & $-\$ 429$ & 0.511 & $-1,710$ to 852 \\
\hline \multicolumn{7}{|l|}{ General+regional block (ref) } \\
\hline Spinal & 0.15 & 0.360 & -0.17 to 0.48 & -255 & 0.688 & $-1,501$ to 991 \\
\hline General & 0.27 & 0.109 & -0.06 to 0.61 & 228 & 0.673 & -832 to 1,288 \\
\hline \multicolumn{7}{|l|}{ Private insurance (ref) } \\
\hline Medicaid & 0.26 & 0.150 & -0.09 to 0.61 & 478 & 0.426 & -700 to 1,656 \\
\hline Medicare & 0.22 & 0.113 & -0.05 to 0.49 & 1,056 & 0.030 & 100 to 2,012 \\
\hline Other insurance & 0.68 & 0.084 & -0.09 to 1.45 & 457 & 0.540 & $-1,008$ to 1,922 \\
\hline Revision & 0.28 & 0.213 & -0.16 to 0.71 & 6,321 & $<0.001$ & 4,590 to 8,052 \\
\hline Female & -0.08 & 0.502 & -0.32 to 0.16 & -909 & 0.030 & $-1,729$ to -89 \\
\hline Age (yr) & 0.02 & 0.003 & 0.01 to 0.03 & -17 & 0.598 & -82 to 47 \\
\hline Body mass index $\left(\mathrm{kg} / \mathrm{m}^{2}\right)$ & 0.03 & 0.002 & 0.01 to 0.06 & 6 & 0.873 & -65 to 76 \\
\hline
\end{tabular}

CI: confidence interval, ref: reference.

cal status, SOI scores, and MP scores have not been thoroughly assessed for their ability to predict discharge locations, LOS, and total costs. We hypothesized that the close association of preoperative rating systems with other patient outcome measures may indicate their value in predicting discharge location as well. The present study found that none of the illness rating systems were significant predictors of discharge to any location, although SOI scores can be leveraged as significant predictors of LOS and total costs.

A striking $77.5 \%$ of TKA patients at this institution were discharged to an ECF, including $62.3 \%$ to SNFs, which is a greater proportion than the $29 \%-49 \%$ of SNF discharges observed in previous studies $^{3,13,14)}$. ASA $\geq 3(\mathrm{p}=0.869)$, SOI major+ $(\mathrm{p}=0.162)$ and SOI minor $(\mathrm{p}=0.112)$, and MP scores of $2(\mathrm{p}=0.370)$ and $3+(\mathrm{p}=0.179)$ were not significant predictors of discharge to any location following TKA. Previous literature found that higher ASA scores trend toward ECF discharge but are not significant, a finding that is supported here ${ }^{13)}$. Although SOI scores are not significantly linked to discharge location, SOI major+ scores clinically tend to predict discharge to ECF $(\mathrm{OR}, 2.23)$ and minor scores tend to predict discharge home (OR, 0.69). Optimizing discharge location remains a challenge as physicians balance the post-acute care needs of patients with the need to reduce costs under bundled payment systems that provide reimbursement per episode rather than reimbursement per service.

The only significant predictors of discharge to an ECF included African-American race (OR, 1.71; $\mathrm{p}=0.016 ; 95 \% \mathrm{CI}, 1.10$ to 2.64 ), increasing age (OR, $1.08 ; \mathrm{p}<0.001 ; 95 \% \mathrm{CI}, 1.05$ to 1.10 ), and increasing BMI (OR, 1.07; $\mathrm{p}<0.001 ; 95 \% \mathrm{CI}, 1.03$ to 1.10 ). Race as a predictive variable has been disputed, with some studies indicating that African-American patients are more likely to be discharged home for self-care ${ }^{15)}$. However, our findings did not differentiate home discharge by level of supportive care and thus align with previous studies citing a greater likelihood of ECF discharge for African-American patients ${ }^{16,17)}$. Increasing age has been previously linked to ECF discharge, with those over 80 years (OR, 5.4) and those 65-79 years (OR, 2.0) more likely to be discharged to an ECF relative to patients under the age of $40^{13,18)}$. TKA patients at this institution also tended to be younger, perhaps influencing the effects of insurance coverage, sex, and discharge location. BMI has not been previously identified as a predictor of discharge to ECF.

Other variables cited in previous research as predictors of discharge location tended toward ECF discharge but did not reach statistical significance. These include Medicaid coverage (OR, $1.69 ; \mathrm{p}=0.064)$, Medicare coverage (OR, $1.51 ; \mathrm{p}=0.153$ ), and fe- 
male sex (OR, 1.34; $\mathrm{p}=0.165)$. Female patients have been shown to experience greater likelihood of ECF discharge, most likely because of reduced caretaker availability at home ${ }^{13,16,18,19)}$. Similarly, Medicare and Medicaid patients trend toward ECF discharge relative to patients covered by private insurance ${ }^{13,16,20}$.

Revision procedures were the only significant, independent predictor of discharge home (OR, $0.41 ; \mathrm{p}=0.001 ; 95 \% \mathrm{CI}, 0.25$ to 0.68 ). While initially surprising because of the greater technical complexity and expected blood loss of revision procedures, this finding is supported by previous research identifying primary procedures $(\mathrm{OR}, 1.4)$ as a significant predictor of discharge to ECF relative to revisions ${ }^{13}$. With the exception of revisions for infection, revision TKA patients are discharged to home at rates similar to or greater than that of primary patients ${ }^{19,21,22)}$.

Only SOI scores of major+ ( $\beta=2.08$ days; $\mathrm{p}<0.001 ; 95 \% \mathrm{CI}, 1.03$ to 3.13 ) and minor ( $\beta=-0.25$ days; $p=0.009 ; 95 \% \mathrm{CI},-0.43$ to -0.06 ) were significant predictors of LOS relative to patients with moderate SOI scores. This represents a statistically and clinically significant finding, as an additional 2.08 days in LOS averages a costly $\$ 5,095$ per day ${ }^{23,24)}$. ASA scores $\geq 3$ were not significant predictors of LOS, supporting previous research that also questioned the association between ASA scores and $\operatorname{LOS}^{25}$. The only other significant predictors of LOS included age $(\beta=0.02 ; p=0.003 ; 95 \%$ CI, 0.01 to 0.03 ) and BMI ( $\beta=0.03 ; p=0.002 ; 95 \%$ CI, 0.01 to 0.06 ). Increasing age has been closely linked to increasing LOS, but BMI has not been previously identified as an independent predictive factor $^{20}$.

Furthermore, only SOI scores were significant predictors of total costs. An SOI of major+ was associated with an average cost increase of $\$ 6,155$ ( $\mathrm{p}=0.022$; 95\% CI, $\$ 877$ to $\$ 11,434$ ) relative to moderate SOI patients. Previous research identified an association between SOI scores and mean total cost, as well as SOI scores and resource utilization ${ }^{11,12)}$. The increase in costs may be linked to the increase in LOS accompanying an SOI of major+. An additional significant predictor of total costs was revision procedures, which added an average of $\$ 6,321$ ( $\mathrm{p}<0.001 ; 95 \% \mathrm{CI}$, $\$ 4,590$ to $\$ 8,052$ ) in total costs. This confirms a previous finding that observed an average increase of $\$ 7,000$ with revision procedures, after controlling for demographic factors ${ }^{10)}$. Medicare ( $\beta=\$ 1,056 ; p=0.030 ; 95 \% \mathrm{CI}, \$ 100$ to $\$ 2,012)$ and female sex ( $\beta=-\$ 909 ; p=0.030 ; 95 \% \mathrm{CI},-\$ 1,729$ to $-\$ 89$ ) were additional statistically significant predictors.

There are several study limitations that must be acknowledged. First, our sample size was relatively small, lacked heterogeneity, and encompasses only a single institution, which may limit generalizability to other healthcare settings. However, the ex- periences of this institution control for the previously cited geographic variance in discharge preference and may inform research for peer institutions ${ }^{13,26)}$. Second, ASA physical status has been identified as a subjective measure with significant interobserver inconsistency, ranging from $31 \%$ to $85 \%$ agreement on ASA classifications among attending physicians ${ }^{27,28}$. Despite this inconsistency, ASA scores are valuable for their widespread use and close association with morbidity and mortality ${ }^{6-8,29)}$. Third, the limited number of patients scoring at the extremes of the scales precluded a nuanced analysis by specific ASA or SOI score. Finally, patient expectations and caregiver support at home were previously identified as predictors of discharge location, but this retrospective analysis could not account for these factors ${ }^{14,30)}$.

\section{Conclusions}

SOI scores appear to be reliable predictors of lengths of stay and total costs following TKA. However, none of the existing preoperative illness rating systems-ASA, SOI, or MP scoressignificantly predicted discharge location for TKA patients. These findings suggest that new models specific to TKA patients should be developed to predict discharge location. While SOI scores can be harnessed to predict additional bed and expenditure needs, models that reliably predict discharge location will enable physicians and hospitals to optimize both outcomes and costs for TKA patients.

\section{Conflict of Interest}

No potential conflict of interest relevant to this article was reported.

\section{References}

1. Mahomed NN, Barrett J, Katz JN, Baron JA, Wright J, Losina E. Epidemiology of total knee replacement in the United States medicare population. J Bone Joint Surg Am. 2005;87: 1222-8.

2. Kurtz S, Ong K, Lau E, Mowat F, Halpern M. Projections of primary and revision hip and knee arthroplasty in the United States from 2005 to 2030. J Bone Joint Surg Am. 2007;89: 780-5.

3. Bozic KJ, Ward L, Vail TP, Maze M. Bundled payments in total joint arthroplasty: targeting opportunities for quality improvement and cost reduction. Clin Orthop Relat Res. 2014;472:188-93. 
4. Kamath AF, Courtney PM, Bozic KJ, Mehta S, Parsley BS, Froimson MI. bundled payment in total joint care: survey of AAHKS membership attitudes and experience with alternative payment models. J Arthroplasty. 2015;30:2045-56.

5. London DA, Vilensky S, O’Rourke C, Schill M, Woicehovich L, Froimson MI. Discharge disposition after joint replacement and the potential for cost savings: effect of hospital policies and surgeons. J Arthroplasty. 2016;31:743-8.

6. Schaeffer JF, Scott DJ, Godin JA, Attarian DE, Wellman SS, Mather RC 3rd. The Association of ASA class on total knee and total hip arthroplasty readmission rates in an academic hospital. J Arthroplasty. 2015;30:723-7.

7. Hooper GJ, Rothwell AG, Hooper NM, Frampton C. The relationship between the American Society of Anesthesiologists physical rating and outcome following total hip and knee arthroplasty: an analysis of the New Zealand Joint Registry. J Bone Joint Surg Am. 2012;94:1065-70.

8. Thakore RV, Lee YM, Sathiyakumar V, Obremskey WT, Sethi MK. Geriatric hip fractures and inpatient services: predicting hospital charges using the ASA score. Curr Gerontol Geriatr Res. 2014;2014:923717.

9. Horn SD, Horn RA, Sharkey PD. The severity of illness index as a severity adjustment to diagnosis-related groups. Health Care Financ Rev. 1984;Suppl:33-45.

10. Bozic KJ, Katz P, Cisternas M, Ono L, Ries MD, Showstack J. Hospital resource utilization for primary and revision total hip arthroplasty. J Bone Joint Surg Am. 2005;87:570-6.

11. Bozic KJ, Rubash HE, Sculco TP, Berry DJ. An analysis of medicare payment policy for total joint arthroplasty. J Arthroplasty. 2008;23(6 Suppl 1):133-8.

12. Lavernia CJ, Laoruengthana A, Contreras JS, Rossi MD. All-Patient Refined Diagnosis-Related Groups in primary arthroplasty. J Arthroplasty. 2009;24(6 Suppl):19-23.

13. Bozic KJ, Wagie A, Naessens JM, Berry DJ, Rubash HE. Predictors of discharge to an inpatient extended care facility after total hip or knee arthroplasty. J Arthroplasty. 2006;21(6 Suppl 2):151-6.

14. Halawi MJ, Vovos TJ, Green CL, Wellman SS, Attarian DE, Bolognesi MP. Patient expectation is the most important predictor of discharge destination after primary total joint arthroplasty. J Arthroplasty. 2015;30:539-42.

15. Nguyen-Oghalai TU, Ottenbacher KJ, Kuo YF, Wu H, Grecula M, Eschbach K, Goodwin JS. Disparities in utilization of outpatient rehabilitative care following hip fracture hospitalization with respect to race and ethnicity. Arch Phys Med Rehabil. 2009;90:560-3.
16. Schwarzkopf R, Ho J, Snir N, Mukamel DD. Factors influencing discharge destination after total hip arthroplasty: a California State Database Analysis. Geriatr Orthop Surg Rehabil. 2015;6:215-9.

17. Jorgenson ES, Richardson DM, Thomasson AM, Nelson CL, Ibrahim SA. Race, rehabilitation, and 30-day readmission after elective total knee arthroplasty. Geriatr Orthop Surg Rehabil. 2015;6:303-10.

18. Gholson JJ, Pugely AJ, Bedard NA, Duchman KR, Anthony CA, Callaghan JJ. Can we predict discharge status after total joint arthroplasty? A calculator to predict home discharge. J Arthroplasty. 2016;31:2705-9.

19. Barsoum WK, Murray TG, Klika AK, Green K, Miniaci SL, Wells BJ, Kattan MW. Predicting patient discharge disposition after total joint arthroplasty in the United States. J Arthroplasty. 2010;25:885-92.

20. El Bitar YF, Illingworth KD, Scaife SL, Horberg JV, Saleh KJ. hospital length of stay following primary total knee arthroplasty: data from the Nationwide Inpatient Sample database. J Arthroplasty. 2015;30:1710-5.

21. Walker WC, Keyser-Marcus LA, Cifu DX, Chaudhri M. Inpatient interdisciplinary rehabilitation after total hip arthroplasty surgery: a comparison of revision and primary total hip arthroplasty. Arch Phys Med Rehabil. 2001;82:129-33.

22. Vincent KR, Vincent HK, Lee LW, Weng J, Alfano AP. Outcomes after inpatient rehabilitation of primary and revision total hip arthroplasty. Arch Phys Med Rehabil. 2006;87:102632.

23. Kester BS, Williams J, Bosco JA, Slover JD, Iorio R, Schwarzkopf R. The association between hospital length of stay and 90-day readmission risk for femoral neck fracture patients: within a total joint arthroplasty bundled payment initiative. J Arthroplasty. 2016;31:2741-5.

24. Youngwerth JM, Bartley JB, Yamashita TE, Kutner JS. Characteristics associated with higher cost per day or longer length of stay in hospitalized patients who died during the hospitalization or were discharged to hospice. J Hosp Med. 2011;6:338-43.

25. Michel JP, Klopfenstein C, Hoffmeyer P, Stern R, Grab B. Hip fracture surgery: is the pre-operative American Society of Anesthesiologists (ASA) score a predictor of functional outcome? Aging Clin Exp Res. 2002;14:389-94.

26. Cram P, Ravi B, Vaughan-Sarrazin MS, Lu X, Li Y, Hawker G. what drives variation in episode-of-care payments for primary TKA? An analysis of medicare administrative data. Clin Orthop Relat Res. 2015;473:3337-47. 
27. Ranta S, Hynynen M, Tammisto T. A survey of the ASA physical status classification: significant variation in allocation among Finnish anaesthesiologists. Acta Anaesthesiol Scand. 1997;41:629-32.

28. Mak PH, Campbell RC, Irwin MG; American Society of Anesthesiologists. The ASA physical status classification: inter-observer consistency: American Society of Anesthesiologists. Anaesth Intensive Care. 2002;30:633-40.
29. Johnson CC, Sodha S, Garzon-Muvdi J, Petersen SA, McFarland EG. Does preoperative American Society of Anesthesiologists score relate to complications after total shoulder arthroplasty? Clin Orthop Relat Res. 2014;472:1589-96.

30. Mahomed NN, Koo Seen Lin MJ, Levesque J, Lan S, Bogoch ER. Determinants and outcomes of inpatient versus home based rehabilitation following elective hip and knee replacement. J Rheumatol. 2000;27:1753-8. 